\title{
The Application of Gravity Model in the Investigation of Spatial Structure
}

\author{
Áron Kincses, Géza Tóth \\ Hungarian Central Statistical Office \\ Keleti K. u. 5-7, 1024 Budapest, Hungary \\ E-mail: aron.kincses@ksh.hu; geza.toth@ksh.hu
}

\begin{abstract}
In this paper the authors wish to introduce an application of the gravity model through a concrete example. In their investigation the gravity model was transformed to analyse the impact of accessibility in a way, that not only the size of gravitational forces but their direction can also be measured. Displacements were illustrated by a bidimensional regression. The aim of this paper to give a new perspective to the investigation of spatial structure through a Hungarian example. This makes easier the transport planning and land development modeling. In our work accessibility analysis, gravity modeling, bi-dimensional regression calculations and GIS visualization were performed.
\end{abstract}

Keywords: gravity model; bi-dimensional regression; accessibility; spatial structure; Hungary

\section{Introduction}

The overall goal of modelling is to simplify reality, actual processes and interactions and on the basis of the obtained data to draw conclusions and make forecasts. Models based on gravitational analogy are the tools of spatial interactions of classical regional analyses. They were first applied in the $19^{\text {th }}$ Century $[2,3,4,11,19,21,31]$.

The application of the geographical gravity is confirmed by the theory of experience according to which (just as in time) the things that are closer to each other in space are more related than distant things. This is called the "first law of geography" [25].

There are two basic areas of the application of gravity models based on physical analogy: the spatial flow analysis [7, 16], and the demarcation of catchment areas $[15,17]$. The potential models based on gravitational analogy are the most important groups of accessible models. In general, it can be stated that they are accessible approaches according to which models show potential benefits of the region compared to other regions where the benefits are quantified [20]. 
The use of accessible models in transport-geographical studies is very common. However, when models are used, it is not entirely clear what is actually modelled; because of their complexity their interpretations may be difficult [13]. It should be stressed that accessibility has no universally accepted definition; in empirical studies different methodological background indicators are used (see [9, 10, 29, 30].The gravitational theory is a theory of contact, which examines the territorial interaction between two or more points in a similar way as correlations are analysed in the law of gravitation in physics. According to Dusek [5], despite the analogy, there are significant differences between gravity models used by social sciences and the law of gravitation used in physics. It is worth bearing in mind that "the gravity model is not based on the gravitational law". It is a fundamental statement based on the experience of undeniable statistical character that takes into consideration spatial phenomena. According to this statement, phenomena interact with each other. The phenomena, which are closer to each other in space, are more related than distant phenomena [5 p. 45].

There are a number of differences between the law and the model. In this study, we wish to highlight a new point of view. As a consequence of the spatial interaction, classical gravitational potential models show the magnitude of potential at spatial points. Regarding the law of gravity in physics, the direction of forces cannot be evaded. In our approach each unit area is assigned an attraction direction. That is, in the case of the gravity model (although such spaces are free of vortex) the space is characterized using vectors.

\section{Method}

The universal gravitational law, Newton's gravitational law, states that any two point-like bodies mutually attract each other by a force, whose magnitude is directly proportional to the product of the bodies' weight and is inversely proportional to the square of the distance between them [1] ( $1^{\text {st }}$ formula):

$$
F=\gamma \cdot \frac{m_{1} \cdot m_{2}}{r^{2}}
$$

Where $\gamma$ is the proportional factor, the gravitational constant (independent of time and place).

If $\mathrm{r}$ indicates the radius vector drawn from the mass point number 2 to a mass point number 1 , then $\mathrm{r} / \mathrm{r}$ is the unit vector drawn from 1 towards 2 , thus, the impact of gravitational force on mass point 1 from mass point 2 is in (Equation 2) (Figure 1), which reads

$$
\vec{F}_{1,2}=-\gamma \cdot \frac{m_{1} \cdot m_{2}}{r^{2}} \cdot \frac{\vec{r}}{r}
$$


A gravitational field is set if the gradient $(\mathrm{K})$ can be specified by a direction and magnitude in each point of the range. Since $\mathrm{K}$ is a vector quantity, three numbers (two in plane) are required to be known at each point, for example the right angle components of gradient $\mathrm{K}_{\mathrm{x}}, \mathrm{K}_{\mathrm{y}}, \mathrm{K}_{\mathrm{z}}$, which are functions of the site. However, many fields, including the gravitational field, can be characterized in a more simple way. They can be expressed by a single scalar, the so-called potential function, instead of three values.

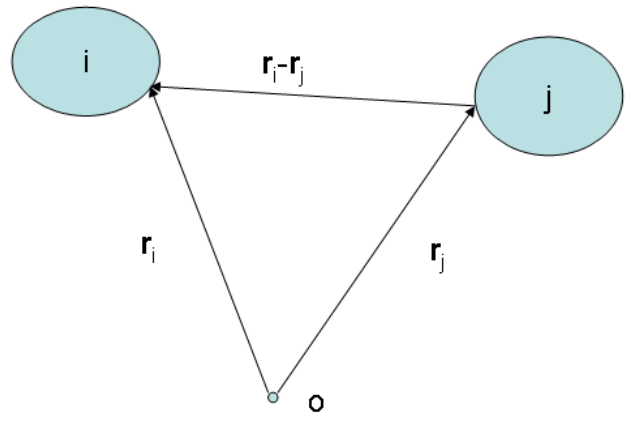

The impact of force on $\mathrm{i}$ by $\mathrm{j}: \quad \overrightarrow{\mathbf{F}}_{\mathrm{ij}}=-\boldsymbol{\gamma} \cdot \frac{\mathbf{m}_{\mathbf{i}} \cdot \mathbf{m}_{\mathbf{j}}}{\mathbf{r}^{2}} \cdot \frac{\overrightarrow{\mathbf{i}}-\overrightarrow{\mathbf{r}}_{\mathbf{j}}}{\mathbf{r}}$

Figure 1

Gravitational power

The potential is in a similar relation with gradient as work and potential energy with force.

Taking advantage of this, gravity models are also applied in most social sciences where space is usually described by a single scalar function, [13], whereas in gravitational law vectors characterizing the space are of great importance. The primary reason for this is that arithmetic operations calculated with numbers are easier to handle than with vectors. Perhaps, we could say that by working with potentials we can avoid calculation problems in problem solving. The potential completely characterizes the whirl-free gravity gravitational field, because there is a definite relationship between the field strength and the potential:

$$
\vec{K}=-\operatorname{grad} U \Rightarrow \quad K_{x}=-\frac{\partial U}{\partial x} ; \quad K_{y}=-\frac{\partial U}{\partial y}
$$

In other words, the potential (as mathematical functional) is the negative gradient of field strength. Various types of potentials and models, which are different from the ones directly based by the gravitational analogy, but in this case, force effects among space power sources are quite different. In fact, these models differ from each other since the attractive forces remain above a predetermined limit value and within set distances. 
The force in a general form is:

$$
|\vec{F}|=C \frac{m_{1}^{\alpha} m_{2}^{\beta}}{r^{\gamma}}
$$

where $\mathrm{C}, \alpha, \beta, \bigvee$ are constants. [14].

However, how they describe actual power relations between social masses is another question.

Although potential models often characterize concentration on focal points of areas and spatial structures, they fail to provide information in which direction and with how much force the social attributes of other areas attract each delimited area unit. Thus, we attempt to use vectors in order to show the direction where the Hungarian micro regions tend to attract micro regions (LAU1) in the economical space compared to their actual geographical position. This analysis can demonstrate the most important centres of attraction, or discrepancies, and the differences between the gravitational orientations of micro-regions can be displayed on a map after the evaluation of data from 2000, 2005 and 2010 has been performed. In the study the geometric centres of specific micro-regions were the co-ordinates of Hungarian micro-regions, which were determined in the EOV co-ordinate system by (Geographical Information System) GIS software.

Our goal can be reached by using Equation (3) to potentials or directly with the help of forces. We chose the latter one.

In the conventional gravity model [21] $\mathrm{D}_{\mathrm{ij}}$ is the "demographic force" between $\mathrm{i}$ and $\mathrm{j}$ where $\mathrm{W}_{\mathrm{i}}$ and $\mathrm{W}_{\mathrm{j}}$ are the population size of the settlements (regions), $\mathrm{d}_{\mathrm{ij}}$ is the distance between $\mathrm{i}$ and $\mathrm{j}$, and finally, $\mathrm{g}$ is the empirical constant (Equation 5).

$$
D_{i j}=g \cdot\left(\frac{W_{i} \cdot W_{j}}{d_{i j}^{2}}\right)
$$

In this study, the $\mathrm{W}_{\mathrm{i}}$ and $\mathrm{W}_{\mathrm{j}}$ weight factors represent personal income, which is the base of the income tax in small communities, dij is the actual distance between $i$ and $j$ regional centres measured on road by a minute (regardless of the traffic conditions and only the maximum speed depending on the road type is taken into consideration).

By generalizing the aforementioned formula, we write the following equation (Equation 6 and 7): 


$$
\begin{aligned}
& D_{i j}=\left|\vec{D}_{i j}\right|=\frac{W_{i} \cdot W_{j}}{d_{i j}^{c}} \\
& \vec{D}_{i j}=-\frac{W_{i} \cdot W_{j}}{d_{i j}^{C+1}} \cdot \vec{d}_{i j}
\end{aligned}
$$

Where $\mathrm{W}_{\mathrm{i}}$ and $\mathrm{W}_{\mathrm{j}}$ are the masses, $\mathrm{d}_{\mathrm{ij}}$ is the distance between them, c is a constant, which is the change of the intensity of inter-regional relations as a function of distance. As the exponent, c, increases and the intensity of inter-regional relations becomes more sensitive to distance, this significance of masses gradually decreases [5]. The minus sign express mathematically, that the masses attract each other (see Figure 1).

With the extension of the above Equation we cannot only measure the strength of the force between the two regions, but its direction as well.

While performing calculations, it is worth dividing the vectors into $\mathrm{x}$ and $\mathrm{y}$ components and summarize them separately. To calculate the magnitude of this effect (vertical and horizontal forces of components) the following Equations are required (Equation 8 and 9), which follow from (6):

$$
\begin{aligned}
& D_{i j}^{X}=-\frac{W_{i} \cdot W_{j}}{d_{i j}^{c+1}} \cdot\left(x_{i}-x_{j}\right) \\
& \mathrm{D}_{\mathrm{ij}}^{\mathrm{Y}}=-\frac{\mathrm{W}_{\mathrm{i}} \cdot \mathrm{W}_{\mathrm{j}}}{\mathrm{d}_{\mathrm{ij}}^{\mathrm{c}+1}} \cdot\left(\mathrm{y}_{\mathrm{i}}-\mathrm{y}_{\mathrm{j}}\right)
\end{aligned}
$$

Where $\mathrm{x}_{\mathrm{i}}, \mathrm{x}_{\mathrm{j}}, \mathrm{y}_{\mathrm{i}}, \mathrm{y}_{\mathrm{j}}$ are the coordinates of the $\mathrm{i}$ and $\mathrm{j}$ regions.

However, if we perform the calculation on all unit areas involved, we will know in which direction their forces exactly act and how strongly they affect the given unit area. (Equation 10)

$$
\begin{aligned}
& D_{i}^{X}=-\sum_{j=1}^{n} \frac{W_{i} \cdot W_{j}}{d_{i j}^{c+1}} \cdot\left(x_{i}-x_{j}\right) \\
& D_{i}^{Y}=-\sum_{j=1}^{n} \frac{W_{i} \cdot W_{j}}{d_{i j}^{c+1}} \cdot\left(y_{i}-y_{j}\right)
\end{aligned}
$$


It should be noted that while in potential models, the results are modified by the introduction of "self-potential", in the examination of forces we disregard the introduction of "self- forces".

Thus, it is possible to determine the magnitude and direction of force in which other areas affect each territorial unity. The direction of the vector, which is assigned to the region, determines the attraction direction of other unit areas, while the length of the vector is proportional to magnitude of force. For the sake of mapping and illustration, we transformed the received forces into shifts proportional to them in the following way (Equation 11 and 12):

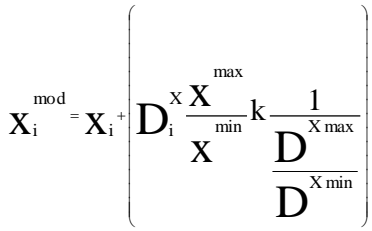

$$
\begin{aligned}
& \mathrm{y}_{\mathrm{i}}^{\bmod }=\mathrm{y}_{\mathrm{i}}^{+}\left(\mathrm{D}_{\mathrm{i}}^{\mathrm{Y}} \frac{\mathrm{y}^{\max }}{\mathrm{y}^{\min }} \mathrm{k} \frac{1}{\frac{\mathrm{D}^{\mathrm{Y}_{\max }}}{\mathrm{D}^{\mathrm{Ymin}}}}\right)
\end{aligned}
$$

Where $X_{i}$ mod and $Y_{i}$ mod are the coordinates of new points modified by the gravitational force, $\mathrm{x}$ and $\mathrm{y}$ are the coordinates of the original point set, the extreme values of which are $x_{\max }, y_{\max }, a x_{\min }, y_{\min }, D_{i}$ is the force along the $\mathrm{x}$ and $\mathrm{y}$ axes, $\mathrm{k}$ is a constant and in this case it is 0.5 . This has the effect of normalizing the data magnitudes.

We assume that in our model the amount of interactions between the „masses” is the same as in Equation 7, and based on the superposition principle, it can be calculated for a given region by Equation 10. The new model cannot directly be compared with transport-geographical data, but the results compared with traffic data in potential models to verify our model [13].

Our model is a kind of complement to the potential models that ensures a deeper insight into them. In the following sections of this study we intend to communicate some significant results of this model.

\section{Application of Bi-Dimensional Regression}

The point set obtained by the gravitational calculation $\left(\mathrm{W}_{\mathrm{i}}\right.$ is the population size of the $\mathrm{i}$. micro-region in Hungary, $\mathrm{d}_{\mathrm{ij}}$ is the distance between $\mathrm{i}$ and $\mathrm{j}$ micro-regions), is worth comparing with the baseline point set, that is, with the actual real-world geographic coordinates and examining how the space is changed and distorted by 
the field of force. The comparison, of course, can be done by a simple cartographic representation, but with such a large number of points, it is not really promising good results. It is much better to use a bi-dimensional regression.

The bi-dimensional regression is one the methods of comparing partial shapes. The comparison is possible only if one of the point coordinates in the coordinate systems differing from each other is transformed to another coordinate system by an appropriate rate of displacement, rotation and scaling. Thus, it is possible to determine the degree of local and global similarities of shapes as well as their differences that are based on the unique and aggregated differences between the points of the shapes transformed into a common coordinate system. The method was developed by Tobler, who published a study describing this procedure in 1994 after the precedents of the 60s and 70s [23, 24, 26, 27, 28]. There are many examples using this procedure, which are not necessarily motivated by geographic issues $[12,22,18]$.

As for the equation relating to the calculation of the Euclidean version, see [27, 8, $6]$.

Table 1

The equation of the two dimensional regression of Euclidean

\begin{tabular}{|l|l|}
\hline 1. Equation of the regression & $\left(\begin{array}{l}A^{\prime} \\
B^{\prime}\end{array}\right)=\left(\begin{array}{l}\alpha_{1} \\
\alpha_{2}\end{array}\right)+\left(\begin{array}{ll}\beta_{1} & -\beta_{2} \\
\beta_{2} & \beta_{1}\end{array}\right) *\left(\begin{array}{l}X \\
Y\end{array}\right)$ \\
\hline 2. Scale difference & $\Phi=\sqrt{\beta_{1}^{2}+\beta_{2}^{2}}$ \\
\hline 3. Rotation & $\Theta=\tan ^{-1}\left(\frac{\beta_{2}}{\beta_{1}}\right)$ \\
\hline 4.Calculation of $\beta_{1}$ & $\beta_{1}=\frac{\sum\left(a_{i}-\bar{a}\right)^{*}\left(x_{i}-\bar{x}\right)+\sum\left(b_{i}-\bar{b}\right)^{*}\left(y_{i}-\bar{y}\right)}{\sum\left(x_{i}-\bar{x}\right)^{2}+\sum\left(y_{i}-\bar{y}\right)^{2}}$ \\
\hline 5.Calculation of $\beta_{2}$ & $\beta_{2}=\frac{\sum\left(b_{i}-\bar{b}\right)^{*}\left(x_{i}-\bar{x}\right)-\sum\left(a_{i}-\bar{a}\right)^{*}\left(y_{i}-\bar{y}\right)}{\sum\left(x_{i}-\bar{x}\right)^{2}+\sum(y-\bar{y})^{2}}$ \\
\hline 6. Horizontal shift & $\alpha_{1}=\bar{a}-\beta_{1} * \bar{x}+\beta_{2} * \bar{y}$ \\
\hline 7. Vertical Shift & $\alpha_{2}=\bar{b}-\beta_{2} * \bar{x}-\beta_{1} * \bar{y}$ \\
\hline 8. Correlation based on error terms & $\mathrm{r}=\sqrt{1-\frac{\sum}{\left.\sum\left(\mathrm{a}_{\mathrm{i}}-\mathrm{a}_{\mathrm{i}}^{\prime}\right)^{2}+\left(\mathrm{b}_{\mathrm{i}}-\mathrm{b}_{\mathrm{i}}^{\prime}\right)^{2}\right]}}$ \\
\hline $\begin{array}{l}\text { 9. Breakdown of the square sum of the } \\
\text { difference }\end{array}$ & $\left.\sum\left[\mathrm{a}_{\mathrm{i}}-\overline{\mathrm{a}}\right)^{2}+\left(\mathrm{b}_{\mathrm{i}}-\overline{\mathrm{b}}\right)^{2}\right]$ \\
\hline & $\left.\sum\left[\mathrm{a}_{\mathrm{i}}-\overline{\mathrm{a}}\right)^{2}+\left(\mathrm{b}_{\mathrm{i}}-\overline{\mathrm{b}}\right)^{2}\right]=$ \\
\hline 10. Calculation of A' & $\mathrm{SST}=\mathrm{SSR}+\mathrm{SSE}$ \\
\hline 11. CALCULATION of B' & $A^{\prime}=\alpha_{1}+\beta_{1}(X)-\beta_{2}(Y)$ \\
\hline & $B^{\prime}=\alpha_{2}+\beta_{2}(X)+\beta_{1}(Y)$ \\
\hline
\end{tabular}


Where $\mathrm{x}$ and $\mathrm{y}$ are the coordinates of independent shapes, $\mathrm{a}$ and $\mathrm{b}$ are the coordinates of dependent shapes, and represent the coordinates of dependent shapes in the system of independent shapes. $\alpha_{1}$ determines the measure of horizontal shift, while $\alpha_{2}$ determines the measure of vertical shift. $\beta_{1}$ and $\beta_{2}$ are the scalar difference and $(\Phi)$ and $(\Theta)$ determine the angle of shifting.

SST is the total square sum of difference. SSR is the square sum of difference explained by regression. SSE is the square sum of difference not explained by the regression (residual). Further details about the background of the two-dimensional regression can be seen in [6 pp. 14-15].

Table 2

Two-dimensional regression between the gravitational and the geographical space

\begin{tabular}{l|l|l|l|l|l|l|l}
\hline Year & $\mathrm{r}$ & $\alpha_{1}$ & $\alpha_{2}$ & $\beta_{1}$ & $\beta_{2}$ & $\Phi$ & $\Theta$ \\
\hline 2000 & 0,942 & 6304,48 & 2017,44 & 0,99 & 0,00 & 0,99 & 0,00 \\
\hline 2005 & 0,942 & 6030,56 & 2012,23 & 0,99 & 0,00 & 0,99 & 0,00 \\
\hline 2010 & 0,941 & 8026,79 & 2632,29 & 0,99 & 0,00 & 0,99 & 0,00
\end{tabular}

\begin{tabular}{l|c|c|c}
\hline Year & SST $(\%)$ & SSR $(\%)$ & SSE $(\%)$ \\
\hline 2000 & 100,00 & 98,73 & 1,27 \\
\hline 2005 & 100,00 & 98,74 & 1,26 \\
\hline 2010 & 100,00 & 98,69 & 1,31
\end{tabular}

Source: own calculation

Our results show that there is a strong relation between the two point systems; the transformed version from the original point set can be obtained without using rotation $(\Theta=0)$. Essential ratio difference between the two shapes was not observed. Comparing the obtained results, it is obvious that the set of points behaves like a single-centre mid-point similarity, when it is diminished. This means that only the attractive force of Budapest can be determined at a national level.

\section{Map Display and Direction Analyses}

The aforementioned statement can be illustrated by a map display of a twodimensional regression. The Darcy program can be used in the application (http://www.spatial-modelling.info/Darcy-2-module-decomparaison).

The square grid attached onto the shape-dependent coordinate system and its interpolated modified position further generalizes the information received from the participating points. 
The arrows in Figures 2 and 3 show the directions of the shifts, while the darker shades illustrates the type of distortion. The darker zones express the divergent forces of the area, which are considered to be the most important gravitational displacements.

The data in Table 2 shows that the space shaped by the gravity model causes only a slight distortion compared to the geographic space. The magnitude of vertical and horizontal displacements increased slightly in 2010.

Practically, the maps produced by Darcy software verify this (Figure 2 and Figure 3 ). It can be seen that the capital of Hungary is Hungary's main centre of gravity, the centre towards which the largest power is attracted. The regional centres like Györ, Pécs, Szeged, Debrecen are also gravity nodes. The national role of regional centres is weak. In the area of Budapest a gravity fault line emerges.

The reason for this phenomenon is that the Hungarian capital attracts all the micro-regions, while very weak forces are applied to Budapest compared to its mass.

The map also illustrates that the regular force fields are the major transport corridors, namely they are slightly distorted due to highways. Between 2000 and 2010, the significance of green-marked gravitational nodes increased. The comparison of the two maps clearly shows the intensification of regional differences.

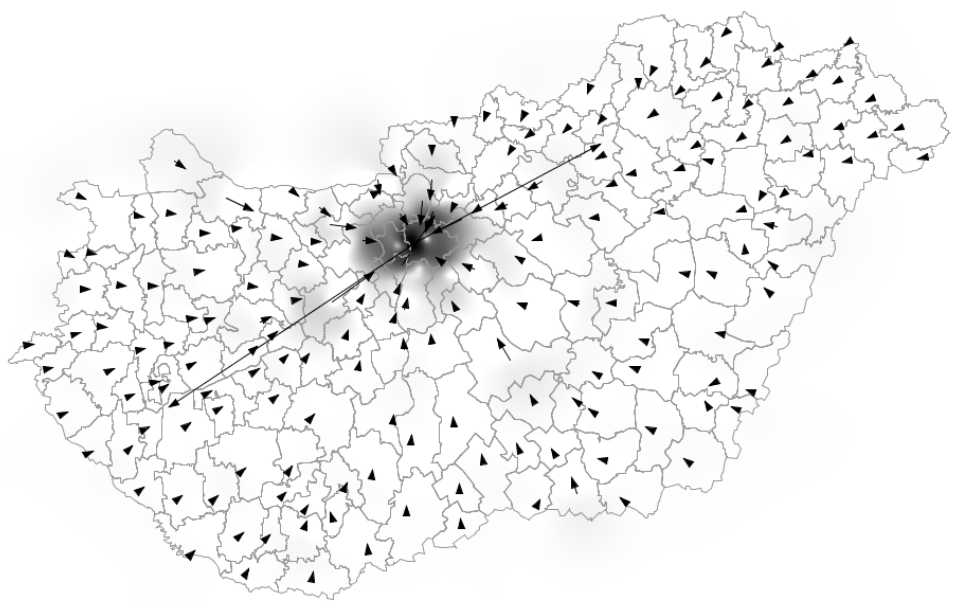

Figure 2

Results in 2000 


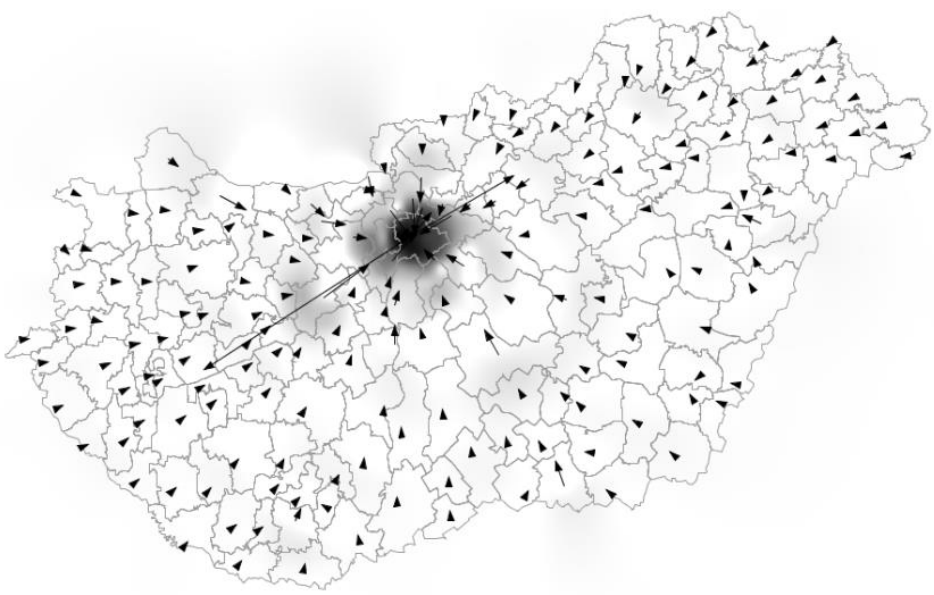

Figure 3

Results in 2010

Based on the obtained results, micro-regions can be grouped by the direction of force applied to them by other micro-regions. Four groups can be formed. They are as follows:

South and West,

North and West,

North and East,

South and East.

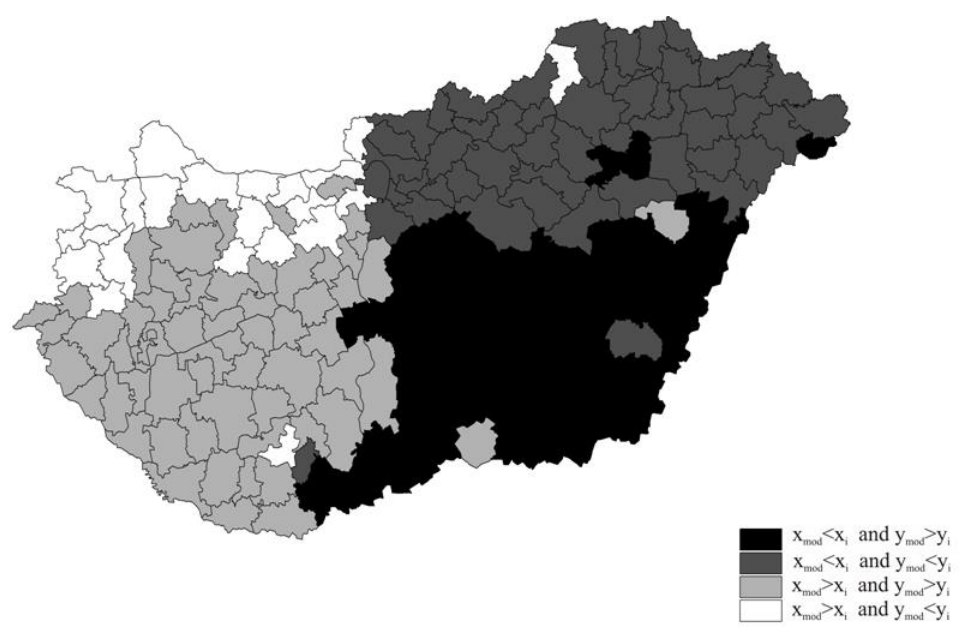

Figure 4

Results in 2000 


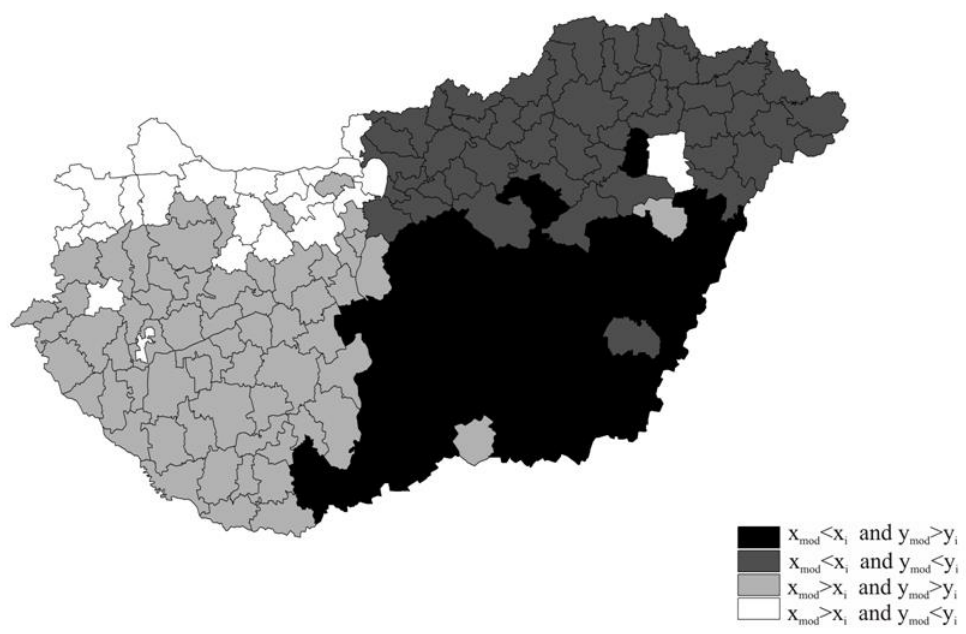

Figure 5

Results in 2010

All micro-regions can be placed in one of the aforementioned groups. The results are shown in Figure 4 and Figure 5. On the maps the North-South segmentation appears more significantly than the East-West one. This statement is especially true in Western Hungary where the developed micro-regions of Gyor-MosonSopron and Komárom-Esztergom Counties attract other micro- regions of Transdanubia. The effect of the east-west gradient can hardly be demonstrated because of the central location of Budapest and its strong impact on the whole country.

The impact of regional centres is clearly seen in the areas where the direction of forces differs from its environment, i.e., in the neighbouring areas where colours are different from the ones in their environment. According to the results of 2000 and 2010 years, stable local centres can be seen in the micro-regions of Debrecen, Miskolc, Nyíregyháza, Szeged and Pécs.

In the advanced territories of northwestern Hungary a similar phenomenon, though less distinctive, is seen when micro-regions differentiate from their environment, since several micro-regional groups tend to be similar in character in these areas.

\section{Magnitude of Force Per Unit Mass}

In a micro-region other regions apply different forces. However, the same force strength fails to result the same impact due to the difference of masses. It is 
possible to calculate the forces acting on a unit of internal mass by the Equation 13:

$$
\mathrm{F}=\frac{\sqrt{\mathrm{D}_{\mathrm{i}}^{\mathrm{X}^{2}+\mathrm{D}_{\mathrm{i}}^{\mathrm{Y}^{2}}}}}{\mathrm{w}_{\mathrm{i}}}
$$

Where $\mathrm{F}$ is the force per unit mass, $\mathrm{D}_{\mathrm{i}}$ is the vertical and horizontal forces and $\mathrm{w}_{\mathrm{i}}$ is the own weight of point $\mathrm{i}$.

As it is shown in Figure 6, the most significant forces compared to their own mass are the micro-regions located in Budapest agglomeration, especially the Budaörs micro-region. Outside the agglomeration, Tata micro-region shows an outstanding magnitude. The micro-regions that represent higher than the average value are mainly located further from Budapest, generally along motorways. The long arrows around Budapest were formed due to the impact of the motorways.

Figure 6 shows the changes between 2000 and 2010. The most significant changes are the outcomes of the construction of motorways. A perfect example for this is Tiszavasvári and Komló micro-regions, which are located near M3 and M6 motorways. Somewhat different examples are the famous Sarkadi and Sárvár micro-regions. In their cases, the decrease of their own weight caused a specific power growth. There is a micro-region, which emerged primarily due to the population growth in its environment and to its gravitational force growth. It is Pilisvörösvár micro-region.

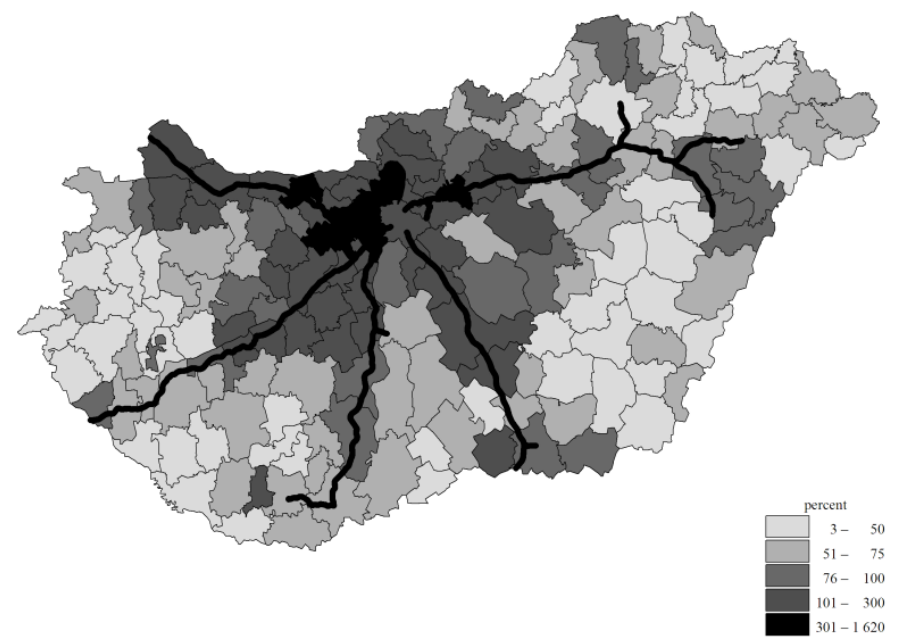

Figure 6

Forces per unit mass (population) as a percentage of the national average in 2010 


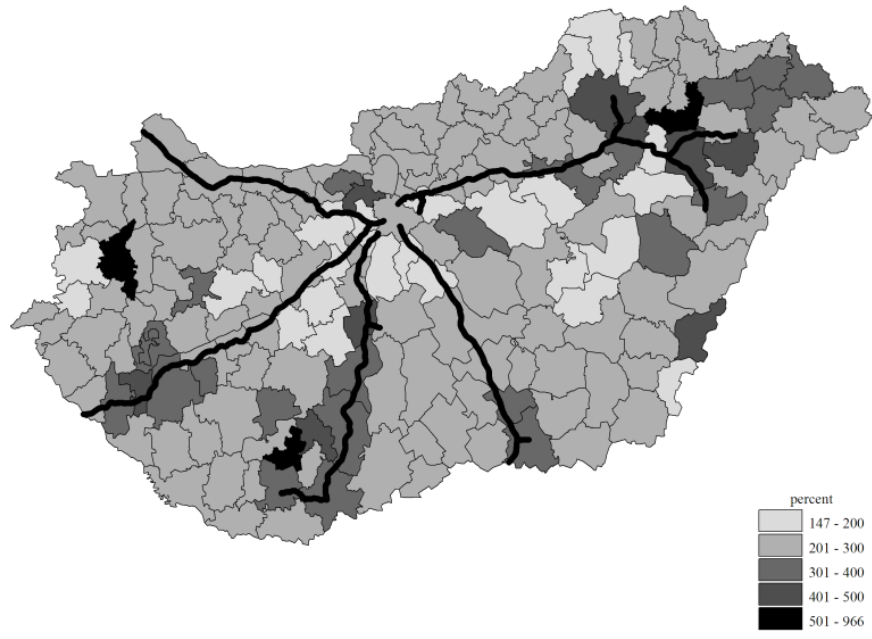

Figure 7

Changes in forces per unit mass (population) in 2000 and in 2010

\section{Conclusions}

In our study we made an attempt to introduce the potential and unexplored areas of gravity models and problems of their interpretation by expanding and extending the methodology. The forces applied were illustrated by using the income tax base as weights in micro-regions of Hungary. On the basis of the model, the result in line with the experience illustrated that Budapest has no counterweight in Hungary and the local central areas are weak. However, the presence of stable local centres is detectable in Debrecen, Miskolc, Nyíregyháza, Szeged and Pécs micro-regions.

It is important to note that compared to their weight, micro-regions affected by the most significant forces are located in the broader vicinity of Budapest, mainly along highways. Most significant changes compared to unit mass are caused by highways, but in many cases the population decline in micro-regions is also a determining factor.

\section{Acknowledgement}

This work was supported by the János Bolyai Research Scholarship of the Hungarian Academy of Sciences.

\section{References}

[1] Budó, Á.: Experimental Physics I. National Textbook Press, Budapest, 2004

[2] Bhattacherjee, A.: Social Science Research: Principles, Methods, and Practices. USF Tampa Bay Open Access Textbooks Collection. Book 3, 2012 
[3] Converse P. D. New Laws of Retail Gravitation. Journal of Marketing, Vol. 14, Issue 3, 1949, pp. 379-384

[4] Dodd S. G.: The Interactance Hypothesis. A Gravity Model Fitting Physical Masses and Human Groups. American Sociological Review, Vol. 15, Issue 2, 1950, pp. 245-256

[5] Dusek, T. :A gravitációs modell és a gravitációs törvény összehasonlítása. Tér és Társadalom, Vol. 17, Issue 1, 2003, pp. 41-57

[6] Dusek. T.: Kétdimenziós regresszió a területi kutatásokban. Területi Statisztika, Vol. 51, Issue 1, 2011, pp. 11-22

[7] Filippo, S.,Maritan, A., Néda, Z: Continuum Approach for a Class of Mobility Models, [physics.soc-ph] 19 Jun 2012, http://arxiv.org/pdf/1206.4359.pdf

[8] Friedman, A., Kohler, B.: Bidimensional Regression: Assessing the Configural Similarity and Accuracy of Cognitive Maps and Other TwoDimensional Data Sets. Psychological Methods, Vol. 8, Issue 4, 2003, pp. 468-491

[9] Geurs, K. T, van Wee, B.: Accessibility Evaluation of Land-Use and Transport Strategies: Review and Research Directions. Journal of Transport Geography, Vol. 12, Issue 2, 2004, pp. 127-140

[10] Gutierrez, J.: Location, Economic Potential and Daily Accessibility: an Analysis of the Accessibility Impact of the High-Speed Line MadridBarcelona-French border. Journal of Transport Geography, Vol. 9, Issue 4, 2001, pp. 229-242

[11] Rodrigue, J. P.: The Geography of Transport Systems. Routledge, New York, 2013

[12] Kare, S., Samal, A., Marx, D.: Using Bidimensional Regression to Assess Face Similarity. Machine Vision and Applications Vol. 21, Issue 3, 2010, pp. $261-274$

[13] Kincses, Á., Tóth, G.: Geometry of Potential Modells. Regional Statistics Vol. 52, Special Issue, 2012, pp. 74-89

[14] M. Barthélemy: Spatial Network. Physics Reports, Vol. 499, 2011, pp. 1101, http://arxiv.org/abs/1010.0302

[15] Vieira, M. S., Vasconcelos, G., Nagel, S.: Dynamics of Spring-Block Models: Tuning to Criticality Phys. Rev. E., Vol. 47, Issue 4, 1993, R2221R2224

[16] Martinez-Zarzoso, I., Nowak-Lehmann, F.: Augmented Gravity Model. An Empirical Application to Mercosur-European Union trade flows. Journal of Applied Economics, Vol. 6, Issue 2, 2003, pp. 291-316 
[17] Mate, G., Neda, Z., Benedek, J.: Spring-Block Model Reveals Region-like Structures. PLoS ONE, Vol. 6, Issue 2, 2011, e16518, doi:10.1371/journal.pone.0016518

[18] Nakaya, T.: Statistical Inferences in Bidimensional Regression Models. Geographical Analysis, Vol. 29, Issue 2, 2010, pp. 169-186

[19] Reilly, W. J.: Methods for the Study of Retail Relationships. University of Texas Bulletin, No. 2944, 1929

[20] Schürmann, C.-Spiekermann, K.-Wegener, M.: Accessibility Indicators. Berichte aus dem Institüt für Raumplanung 39, Dortmund, IRPUD, 1997

[21] Stewart J. Q.: Demographic Gravitation: Evidence and Applications. Sociometry, Vol. 11, Issues 1-2, 1948, pp. 31-58

[22] Symington, A., Charlton, M. E., Brunsdon, C. F.: Using Bidimensional Regression to Explore Map Lineage Computers, Environment and Urban Systems, Vol. 26, Issue 2, 2002, pp. 201-218

[23] Tobler, W. R.: Map Transformations of Geographic Space. PhD dissertation, Seattle, University of Washington, 1961

[24] Tobler, W. R. Computation of the Correspondence of Geographical Patterns. Papers of the Regional Science Association, Vol. 15, Issue 1, 1965, pp. 131-139

[25] Tobler, W. R.: A Computer Model Simulating Urban Growth in the Detroit Region. Economic Geography, Vol. 46, Issue 2, 1970, pp. 234-240

[26] Tobler, W. R.: Comparisons of Plane Forms. Geographical Analysis, Vol. 10, Issue 2, 1978, pp. 154-162

[27] Tobler, W. R.: Bidimensional Regression. Geographical Analysis, Vol. 26, Issue 3, 1994, pp. 187-212

[28] Tobler, W. R.: On the First Law of Geography: A Reply Annals of the Association of American Geographers, Vol. 94, Issue 2, 2004, pp. 304-310

[29] Tschopp, M., Fröhlich, P., Keller, P., Axhausen, K. W.: Accessibility, Spatial Organisation and Demography in Switzerland through 1920 to 2000: First Results. $3^{\text {rd }}$ Swiss Transport Research Conference Monte Verità / Ascona, March 19-21. 2003

[30] Willigers, J., Floor, H., van Wee, B.: Accessibility Indicators for Locational Choice of Offices: An Application to the Intraregional Distributive Effects of High-Speed Rail in the Netherlands. Environment Planning. A Vol. 39, Issue 9, 2007, pp. 2086-2098

[31] Krings, G., Calabrese, F., Ratti, C., Blondel, V. D.: Urban Gravity: a Model for Inter-City Telecommunication Flows. Journal of Statistical Mechanics: Theory and Experiment, Vol. 9, Issue 7, 2009, pp. 1-8 